\title{
Analisa Perbandingan Deteksi Tepi Citra Foto Menggunakan Algoritma Robert dan Prewitt
}

\author{
Septian Rheno Widianto \\ Prodi Teknik Media Digital, \\ Jurusan Teknik Informatika dan Ko mputer \\ Politeknik Negeri Jakarta \\ Jl. Prof. G.A. Siwabessy, Kampus UI. Depok \\ septian.rheno@yahoo.de
}

\author{
Rhyan Edyal \\ Jurusan Sistem Ko mputer \\ Fakultas Ilmu Ko mputer dan Teknologi Informasi \\ Universitas Gunadarma \\ Jl. Margonda Raya No. 100 Depok \\ rhiyan85@g mail.com
}

Diterima: 11 September 2016. Disetujui: 25 Oktober 2016. Dipublikasikan: Nopember 2016

\begin{abstract}
Abstrak - Deteksi tepi pada sebuah gambar dapat dilakukan dengan 4 algoritma, yaitu Sobel, Robert, Prewitt, dan Canny. Algoritma yang akan digunakan pada penelitian ini adalah algoritma Prewitt dan algoritma Robert. Dua algoritma tersebut memiliki sebuah cara yang berbeda, untuk algoritma Prewitt menggunakan operator matrik 3x3, sedangkan algoritma Robert menggunakan operator matrik $2 \times 2$. Dari dua teknik yang berbeda tersebut maka penulis ingin mengimplementasikan teknik keduanya dengan membuat sebuah aplikasi digital image processing untuk mengetahui tingkat perbedaan dari kinerja kedua algoritma. Berdasarkan analisis deteksi tepi Robert menghasilkan sebuah garis tepi lebih jelas dibandingkan dengan Prewitt yang menghasilkan garis tepi seperti masih ada bayang-bayang atau garis tepi rangkap tidak jelas. Hasil kinerja terbaik diantara $\mathbf{1 0}$ data uji sample algoritma Robert dapat dikatakan tingkat keberhasilan mencapai $70 \%$ dalam deteksi yaitu 7 citra dari 10 data uji, sedangkan algoritma Prewitt $30 \%$ atau 3 citra dari 10 data uji yang berhasil diujikan.
\end{abstract}

Kata Kunci : deteksi tepi, algoritma prewitt, algoritma robert.

\section{PENDAHULUAN}

Gambar merupakan presentasi dari hasil foto atau lukisan suatu benda yang nyata, untuk itu gambar dapat dilihat dari berbagai sudut pandang. Salah satunya adalah suatu gambar pemandangan, gambar tersebut merupakan sebuah gambar satu kesatuan yang tanpa menentukan objek dan background [1].

Deteksi tepi dapat dilakukan ketika ingin medeteksi beberapa objek special yang ada pada suatu gambar dengan teknik pemisahan antara objek dan background [2]. Salah satu tujuan dari deteksi tepi adalah ketika akan digunakan untuk recognition atau pengenalan sebuah objek dalam gambar.

Ada empat teknik atau metode untuk deteksi tepi yaitu metode Robert, Canny, Prewitt dan Sobel. Ke empat algoritma tersebut memiliki teknik yang berbeda dalam melakukan deteksi tepi pada suatu gambar, sebab itu kami akan melakukan analisis dari dua buah algoritma Robert dan Prewitt untuk membedakan dan menganalisis keakurasian dalam melakukan deteksi tepi [3].

Objek yang akan penulis olah adalah semua jenis gambar, semua dari isi gambar tersebut akan di deteksi garis tepi. Pada analisis ini penulis akan mencoba mengimplementasikan kedua metode (Robert dan Prewitt) dengan menggunakan Matlab R2016b.

\section{PEMBAHASAN}

Beberapa hal yang menjadi perhatian dalam pembahasan, yaitu :

A. Deteksi Tepi

Deteksi tepi merupakan sebuah segmentasi dari sebuah gambar yang bertujuan untuk mengetahui garis tepi pada sebuah objek dalam gambar atau dengan istilah menandai bagian yang men jadi detail sebuah gambar[4]. Selain itu deteksi citra ini juga bertujuan untuk memperbaiki detail dari citra yang kabur, yang terjadi karena error atau adanya efek dari proses akuisisi gambar.

Suatu titik (x,y) dikatakan sebagai tepi (edge) dari suatu gambar bila titik tersebut mempunyai perbedaan yang tinggi dengan tetangganya[5]. Gambar 1 menggambarkan bagaimana tepi suatu gambar diperoleh.

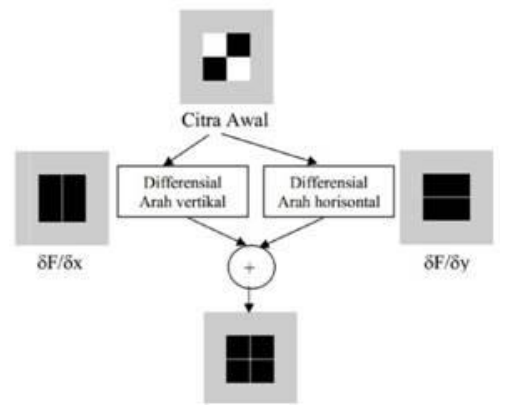

Gambar 1. Proses Pembent ukan Deteksi Tepi Citra

Gambar 1 menjelaskan proses pembentukan sebuah citra yang dilakukan penghitungan differensial terhadap arah vertikal dan differensial 
terhadapt arah horizontal. Gambar 2 merupakan contoh yang dihasilkan dari proses deteksi tepi citra menggunakan model differensial.

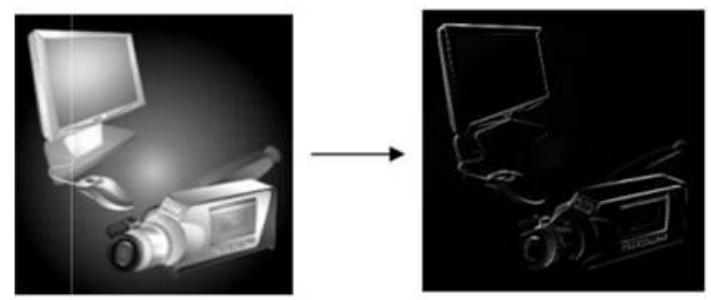

Gambar 2. Hasil Deteksi Tepi Citra

Pada Gambar 2 terlihat bahwa hasil deteksi tepi berupa tepi-tepi dari suatu gambar. Bila diperhatikan bahwa tepi suatu gambar terletak pada titik-titik yang memiliki perbedaan tinggi. Berdasarkan prinsip-prinsip filter pada citra maka tepi suatu gambar dapat diperoleh menggunakan High Pass Filter (HPF), yang mempunyai karakteristik[6]:

$$
\sum_{y} \Sigma_{x} H(x, y)=0
$$

Contoh:

Diketahui fungsi citra $\mathrm{f}(\mathrm{x}, \mathrm{y})$ sebagai berikut:

\begin{tabular}{|l|l|l|l|l|}
\hline 1 & 1 & 1 & 1 & 1 \\
\hline 1 & 1 & 1 & 1 & 0 \\
\hline 1 & 1 & 1 & 0 & 0 \\
\hline 1 & 1 & 0 & 0 & 0 \\
\hline 1 & 0 & 0 & 0 & 0 \\
\hline
\end{tabular}

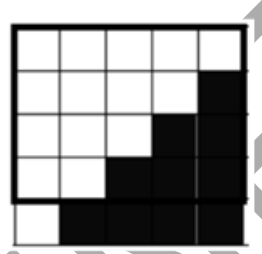

Gambar 3. Hasil Output Sebelum

Dengan menggunakan filter $\mathrm{H}(\mathrm{x}, \mathrm{y})=[-1,1]$, Maka hasil filter adalah :

\begin{tabular}{|l|l|l|l|l|}
\hline 0 & 0 & 0 & 0 & 1 \\
\hline 0 & 0 & 0 & 1 & 0 \\
\hline 0 & 0 & 1 & 0 & 0 \\
\hline 0 & 1 & 0 & 0 & 0 \\
\hline 1 & 0 & 0 & 0 & 0 \\
\hline
\end{tabular}

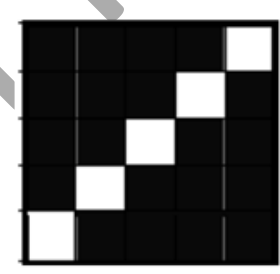

Gambar 4. Hasil Output Sesudah

Terdapat 3 jenis tepi didalam citra digital yaitu :

a. Tepi Curam.

Tepi curam adalah tepi dengan perubahan intensitas yang tajam. Arah tepi berkisar 900[7]. Gambar 5 menunjukkan deteksi tepi tipe tepi curam.

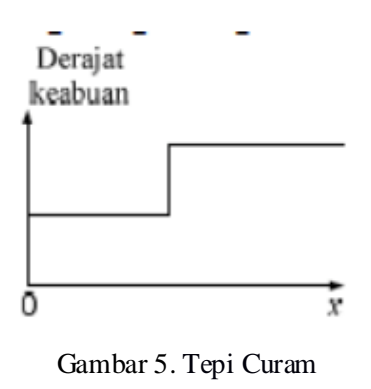

b. Tepi Landai

Tepi landai yaitu tepi dengan sudut arah yang kecil. Tepi landai dapat dianggap terdiri dari sejumlah tepi-tepi lokal yang lokasinya berdekatan. Gambar 6 menunjukkan deteksi tepi tipe tepi landai.

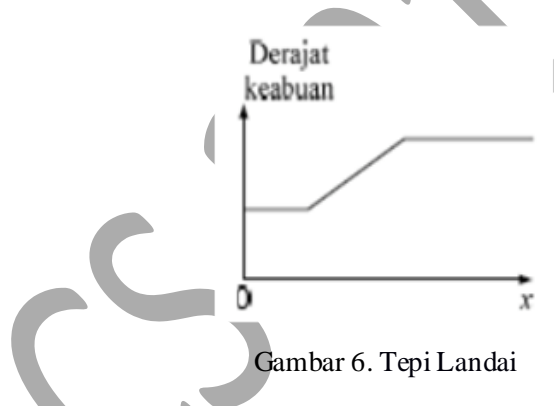

c. Tepi yang mengandung derau.

Umumnya tepi yang terdapat pada aplikasi visi komputer mengandung derau. Operasi peningkatan kualitas citra dapat dilakukan terlebih dahulu sebelum pendektesian tepi [8]. Gambar 7 menunjukkan deteksi tepi tipe tepi curam dengan derau.

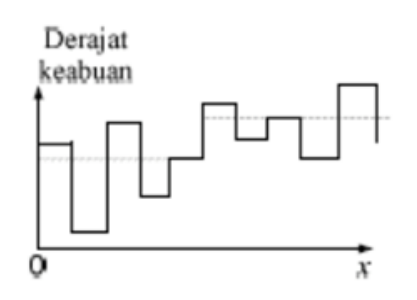

Gambar 7. Tepi Curam Dengan Derau

Ada beberapa metode konvensional yang sering digunakan untuk melakukan deteksi tepi, seperti Robert, Prewitt dan Sobel [3].

\section{B. Algoritma Robert}

Metode Robert adalah nama lain dari teknik differensial yang dikembangkan di atas, yaitu differensial pada arah horizontal dan differensial pada arah vertikal, dengan ditambahkan proses konversi biner setelah dilakukan differensial.

Teknik konversi biner yang disarankan adalah konversi biner dengan meratakan distribusi warna hitam dan putih. Metode Robert ini juga disamakan dengan teknik DPCM (Differential Pulse Code Modulation) [9]. 
Algoritma Robert ini juga disebut sebagai operator silang, radient dari arah-X dan arah-Y dihitung dengan rumus :

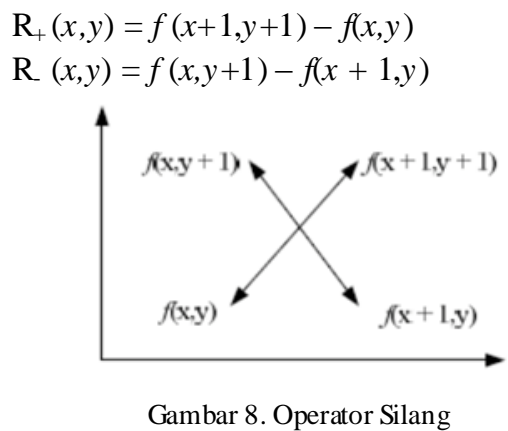

Gambar 8 menunjukkan bahwa operator $\mathrm{R}+$ adalah hampiran turunan berarah dalam arah 450 , sedangkan operator R- adalah hampiran turunan berarah dalam arah 1350. Dalam bentuk maks konvolusi, operator Roberts adalah [10]:

$$
R+=\left[\begin{array}{cc}
1 & 0 \\
0 & -1
\end{array}\right] \quad R-=\left[\begin{array}{cc}
0 & 1 \\
-1 & 0
\end{array}\right]
$$

\section{Algoritma Prewitt}

Metode Prewitt merupakan pengembangan metode robert dengan menggunakan filter HPF yang diberi satu angka nol penyangga [11]. Metode ini mengambil prinsip dari fungsi laplacian yang dikenal sebagai fungsi untuk membangkitkan HPF, bentuk operator yang digunakan pada prewitt adalah:

$H=\left[\begin{array}{lll}-1 & 0 & 1 \\ -1 & 0 & 1 \\ -1 & 0 & 1\end{array}\right]$

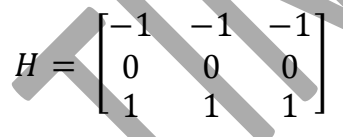

\section{Matlab_R2016b}

MATLAB (Matrix Laboratory) adalah sebuah lingkungan komputasi numerikal dan bahasa pemrograman komputer generasi keempat. Dikembangkan oleh The MathWorks, MATLAB memungkinkan manipulasi matriks, pem-plot-an fungsi dan data, implementasi algorit ma, pembuatan antarmuka pengguna, dan peng-antarmuka-an dengan program dalam bahasa selain Matlab.

Meskipun hanya bernuansa numerik, sebuah kotak kakas (toolbox) yang menggunakan mesin simbolik MuPAD, memungkinkan akses terhadap kemampuan aljabar komputer. Sebuah paket tambahan, Simulink, menambahkan simulasi grafis multiranah dan desain berdasarkan model untuk sistem terlekat dan dinamik [12].

\section{METODOLOGI PENELITIAN}

Penelitian ini menggunakan peralatan komputer, perangkat lunak Matlab_R2016b, dan semua objek citra untuk dideteksi. Langkah-langkah penelitiannya adalah sebagai berikut:

1. Membuat program kedua teknik pendeteksian (Prewitt dan Roberts) menggunakan Matlab_R2016b.

2. Merancang antar muka pemakai, untuk mempermudah melakukan proses uji coba.

3. Menghubungkan program teknik pendeteksian dengan antar mu ka pemakai.

4. Melakukan pendeteksian objek pada sebuah citra yang diuji.

5. Melakukan deteksi tepi pada citra dengan dua metode deteksi tepi. Menentukan nilai pengambangan untuk tiap metode deteksi tepi agar lebih memperlihatkan garis tepi. Nilai pengambangan digunakan pada saat operasi pendeteksian tepi.

Deteksi tepi citra dilakukan mengikuti langkah-langkah berikut:

1. Baca input citra yang akan diproses lalu konversi citra asli men jadi citra abu-abu.

2. Deteksi tepi seluruh citra.

3. Isi celah atau lubang dari citra dengan operator morfologi skala keabu-abuan.

4. Lakukan perbaikan citra dengan fungsi dilasi.

5. Mengembalikan citra biner ke citra RGB yang sudah terdeteksi tepinya.

\section{PEMBAHASAN}

Bertujuan untuk memudahkan user melakukan proses deteksi tepi pada foto, maka dirancang sebuah tampilan user interface menggunakan bahasa pemrograman Matlab_R2016b.

Desain user interface sesuai dengan konsep bahwa citra yang akan dilakukan deteksi adalah smua jen is gambar. Sehingga user pengguna aplikasi akan langsung dapat browse lokasi gambar yang akan diload. Setelah gambar selesai diload maka selanjutnya user dapat melakukan proses segmentasi citra dengan menggunakan teknik algorit ma Prewitt atau juga algorit ma Robert.

Pada penelitian ini akan dilakukan analisis perbandingan mengenai hasil dari kinerja antara algorit ma Prewitt dan algoritma Robert.

\section{A. Hasil Uji Coba dan Analisis.}

Proses pertama setelah upload citra adalah menjalankan system gray yaitu merubah citra dari warna asli menjadi grayscale. Berikut contoh hasil dari implementasi code : 


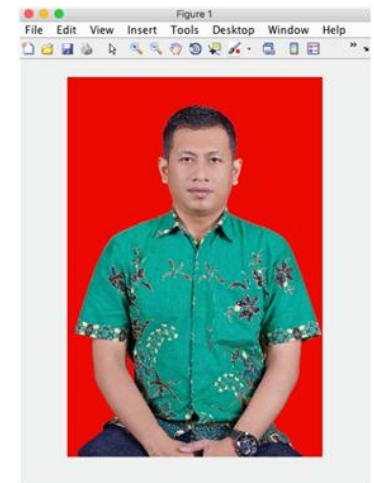

Gambar 9. Citra Asli

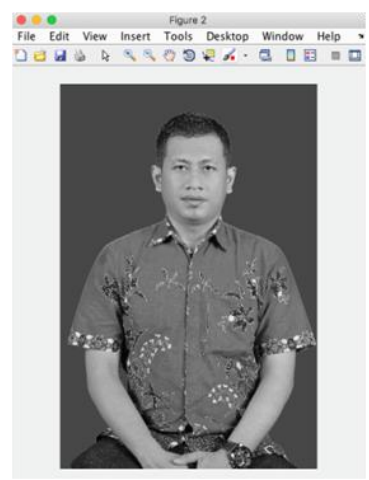

Gambar 10. Hasil Gray

Untuk melakukan analisis dari kedua algoritma deteksi tepi peneliti menggunakan 10 sample citra dengan objek foto bertipe JPEG. Dari 10 data sample hasil output dapat dilihat pada tabel 1.

TABEL 1. HASIL UJI COBA CITRA

\begin{tabular}{|c|c|c|}
\hline Citra Asli & Prewitt & Robert \\
\hline & & \\
\hline & & \\
\hline & & \\
\hline & & \\
\hline
\end{tabular}

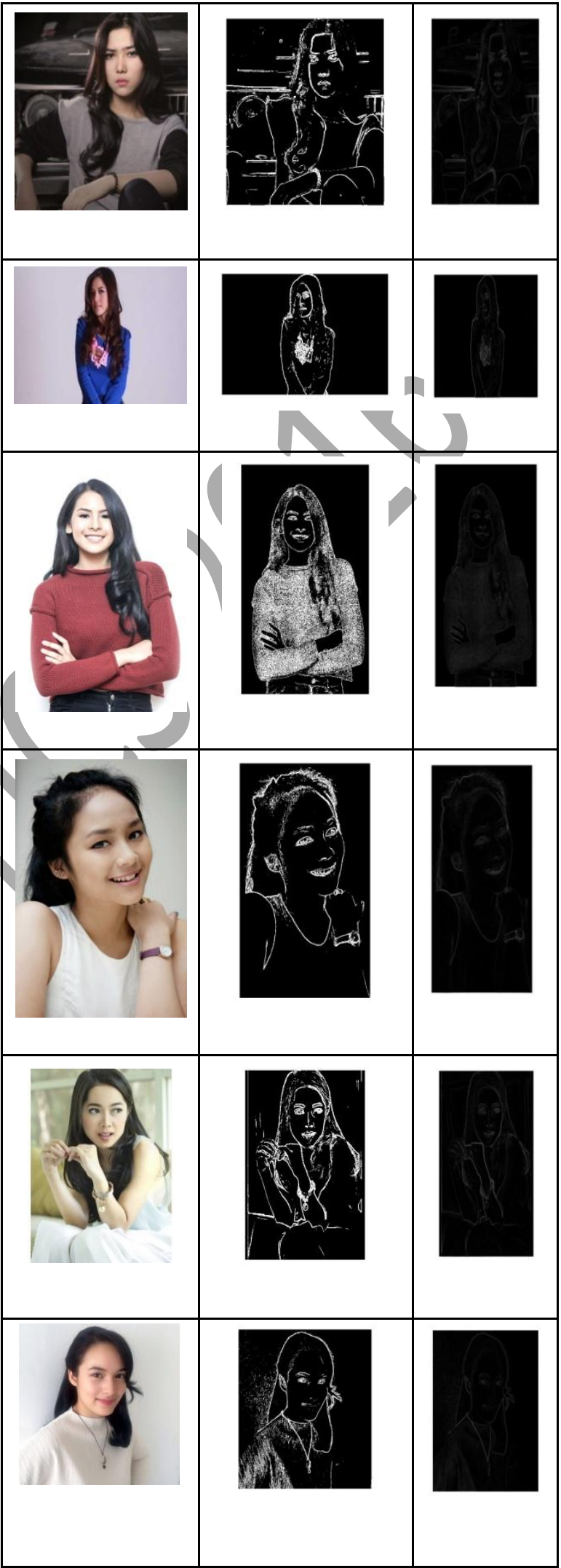




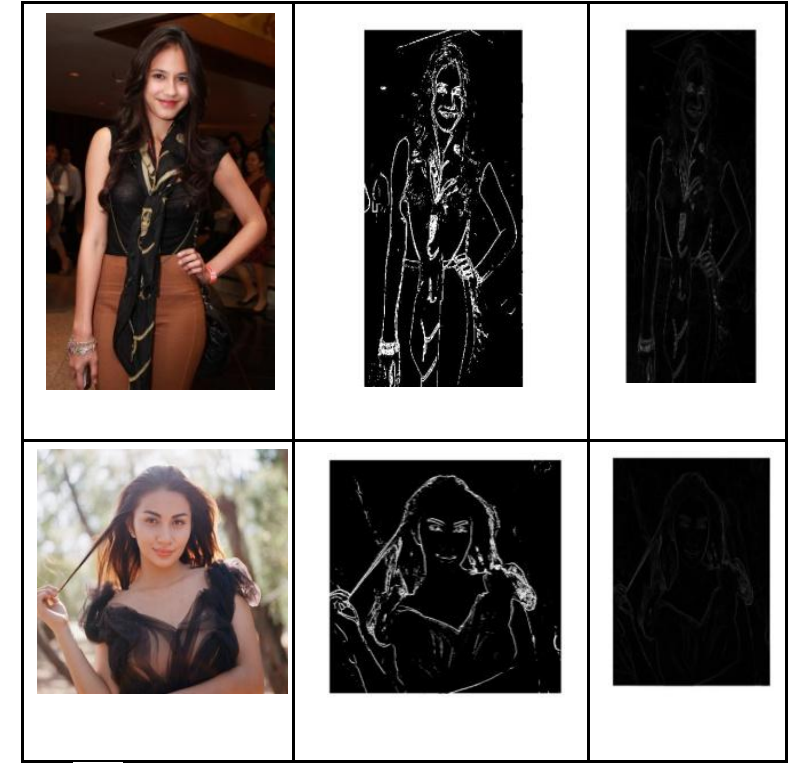

Dari hasil uji coba yang dilakukan, program ini dapat memberikan hasil bahwa metode deteksi tepi algoritma Robert merupakan metode deteksi yang paling akurat dibanding dengan algoritma Prewitt. Dapat dilihat hasil dari deteksi pada tabel 1 hasil deteksi algoritma Robert terlihat lebih halus.

Hasil kinerja terbaik diantara 10 data uji sample algoritma Robert dapat dikatakan tingkat keberhasilan mencapai $70 \%$ dalam deteksi yaitu 7 citra dari 10 data uji, sedangkan algoritma Prewitt $30 \%$ atau 3 citra dari 10 data uji yang berhasil diujikan. Beberapa faktor yang menyebabkan terjadinya kegagalan pada metode deteksi tepi adalah karena efek pencahayaan pada saat pengambilan foto sehingga ada beberapa yang bukan tepi terdeteksi atau yang disebut dengan noise.

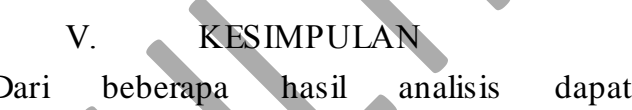
disimpulkan kinerja terbaik dari kedua algoritma tersebut, algoritma Robert memiliki kinerja terbaik baik dari segi hasil, untuk melakukan analisis lebih lanjut diharapkan dapat membuat aplikasi yang lebih baik lagi untuk mendeteksi ke empat jenis metode deteksi tepi dengan bahasa pemrograman selain Matlab supaya dapat digunakan untuk pemanfaatan dalam proses pengolahan citra digital.

\section{REFERENSI}

[1] Chris Solomon and Toby Breckon" Fundamentals of digital image processing : a practical approach with examples in MATLAB'2011 by John Wiley \& Sons, Ltd.

[2] Rajni Nema, Dr A.K Saxena, 2013, "Edge Detection Operators in Digital Image", IJESRT, , SRCEM Bangalore ,ISN 2277-9655, (2013) June.

[3] Gonzalez. R., Woods. R. 1992, Digital Image Processing, Addison Wesley, hal 414-428.
[4] K. Padmapriya, and T. K. Bino, "Boundary Detection using Edge Following Algorithm and Enhancement of the Image", International Conference on Computing and Control Engineering (ICCCE 2012), 12-13 April 2012.

[5] Melin P, Gonzalez CI, Castro JR, Mendoza O, Castillo O. Edge-detection method for image processing based on generalized type-2 fuzzy logic. IEEE Transactions on Fuzzy Systems. 2014 Dec; 22(6):1515-25.

[6] P.Kamboj, V.Rani, Image Enhancement Using Hybrid Filtering T echnique, IJSR, vol. 2(6), 2013, 214-220.

[7] Punam Thakare (2011) "A Study of Image Segmentation and Edge Detection Techniques",

[8] Raman Maini and Dr. Himanshu Aggarwal "Study and Comparison of various Image Edge Detection T echniques" International Journal of Image Processing (IJIP), Vol3: Issue (1).

[9] W.Luo, Efficient Removal of Impulse Noise from Digital Images", IEEE Transactions, 2006, 523527.

[10] R. Maini \& Dr. H. Aggarwal, "Study and Comparison of Various Image Edge Detection Techniques",

[11] S.Lakshmi,Dri V .Sankaranarayanan," A study of Edge Detection Techniques for Segmention Computing Approaches", IJCA special issue on "Computer Aided Soft Computing Techniques for imaging and Biomedical Applications" CASCT ,20.

[12] Rafael C. Gonzalez, Richard E. Woods \& Steven L. Eddins (2004) Digital Image Processing Using MATLAB, Pearson Education Ptd. Ltd, Singapore. 